\section{LOW ABRASIVE, HIGH PERFORMING TOOTHPASTES}

Formulated with the natural cleaning power of baking soda, Arm \& Hammer has low abrasive and high performing toothpastes for everyone.

Sensitive Pro Repair toothpaste has been clinically developed to address the cause of sensitive teeth.

Is the only clinically proven toothpaste on the market that when used regularly for eight weeks, offers lasting relief from sensitivity for up to 16 weeks. It fills and repairs tooth enamel using Liquid Calcium technology and forms a shield to protect exposed nerves.

To make sensitive teeth a thing of the past - contact Arm \& Hammer now.
For more information about the carefully formulated Arm \& Hammer toothpaste range, visit http://www.armandhammer. co.uk/ or email: ukenquiries@ churchdwight.com.

Arm \& Hammer oral healthcare products are available at Boots, Superdrug, Sainsbury's, Tesco, Asda and Morrisons throughout the UK.

\title{
DO YOU SEE PATIENTS WITH DRY MOUTH?
}

Dry mouth can affect as many as one in four patients and can have a significant impact on oral health, as well as physical and psychological wellbeing.

Oralieve products have been specifically designed and tested with dry mouth sufferers to help supplement the natural protective enzyme system in saliva and provide effective, lasting relief for dry mouth.

Free from strong flavours, alcohol and SLS, Oralieve products help maintain oral health and improve comfort for those patients who may be suffering with dry mouth because of diabetes, polypharmacy, Sjögren's syndrome, cancer treatment, depression or dementia. The entire range is available over the counter through Oralieve's online store, Amazon and 500+ Lloyd's Pharmacies, and Oralieve Moisturising Mouth Gel and Moisturising Mouth Spray are also available on prescription from GPs.

To request patient samples and literature, access online CPD modules and further information, visit www.oralieve.co.uk.

Email: hello@oralieve.co.uk. Phone: 01582 439122.

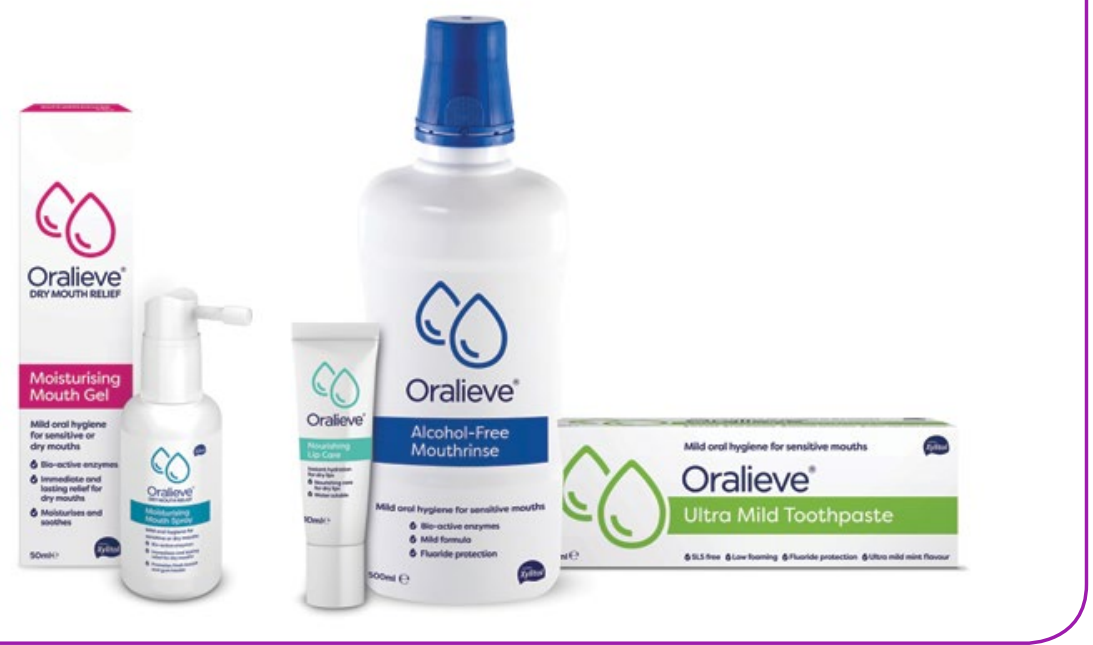

\section{GENTLE AND EFFECTIVE}

CS Toothbrushes from Curaprox are made using Curen filaments, rather than nylon, which makes them gentle yet still incredibly effective. Curaprox is able to pack thousands - as opposed to the hundreds on a standard manual toothbrush - of these filaments on the brush head, which ensures unparalleled cleaning.

Not only that, the small, compact head allows users to reach all areas of the mouth, including those ever-neglected upper molars. The octagonal handle allows a comfortable grip that helps users to position the brush at the correct angle, ensuring the gum line is cleaned effectively.

Make sure you are armed with helpful tools and advice to keep your patients' oral hygiene regime on top form. Contact the friendly team at Curaprox today to discover more about the gentle and effective CS Toothbrushes.

For more information call 01480 862084, email info@curaprox.co.uk or visit www.curaprox.co.uk.

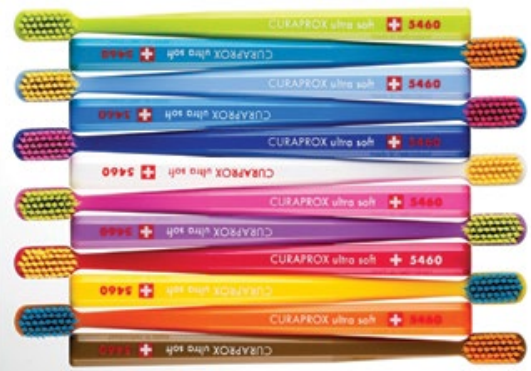

